\title{
No evidence for uniparental disomy as a common cause of Sotos syndrome
}

\author{
Martin Smith, Paul Fullwood, Yu Qi, Sheila Palmer, Meena Upadhyaya, \\ Trevor Cole
}

\begin{abstract}
A number of rare diseases (including Sotos syndrome) of unknown aetiology, which occur mainly sporadically and with features of growth disorder and developmental delay, may be caused by imprinted genes and therefore be associated with UPD. Using 112 dinucleotide repeat DNA polymorphisms, we have examined parental inheritance of all autosome pairs, except chromosome 15, in 29 patients with Sotos syndrome. All informative cases showed biparental inheritance and no cases of UPD were found. We conclude that Sotos syndrome is either not caused by an imprinted gene or that UPD is rare or of a segmental form in its aetiology. ( $($ Med Genet 1997;34:10-12)
\end{abstract}

Keywords: imprinting; growth disorder; developmental delay.

Uniparental disomy (UPD) is the presence of two homologous chromosomes/chromosome segments from a single parent with no corresponding chromosome from the other. ${ }^{12}$ It may be classified as heterodisomy if both uniparental homologues are present, or isodisomy if both are copies of a single uniparental homologue. If the contribution of maternal and paternal alleles were equivalent, UPD would be of no phenotypic consequence except when recessive alleles were present on an isodisomic segment. For some chromosomes, however, both isodisomy and heterodisomy cause distinct syndromes, owing to the presence of genes that are differentially expressed according to their parental origin. This is the phenomenon of genetic imprinting and subjects are functionally hemizygous at such loci. ${ }^{3}$

Observation of the offspring of pairs of mice carrying identical balanced Robertsonian translocations, from which a proportion of UPD would be expected, have shown a range of phenotypes including both normal and abnormal development with early fetal death, disordered growth, and behavioural alterations, depending on the chromosome segment involved. ${ }^{4} \mathrm{~A}$ number of human diseases manifesting some of these features are associated with genetic imprinting and UPD: Prader-Willi syndrome with maternal chromosome 15 UPD or paternal deletions of chromosome 15q11q13 $3^{5}$; Angelman syndrome with paternal chromosome 15 UPD or maternal 15q11-q13 deletion ${ }^{67}$; Beckwith-Weidemann syndrome with paternal chromosome $11 \mathrm{UPD}^{8}$; and Silver-
Russell syndrome with maternal chromosome 7 UPD. ${ }^{9}$

Sotos syndrome is a rare growth disorder first delineated in five children in $1964 .^{10}$ Clinical features include large body size, characteristic facial appearance, advanced bone age, and developmental delay. Cole and Hughes ${ }^{11}$ conducted a clinical study of 40 "classical" cases with follow up data for two to five years. This allowed the refinement of the diagnostic criteria and these, together with the clinical details of the cases, were reported in 1994.

Despite published reports of almost 300 cases, the aetiology of Sotos syndrome remains unknown. Most cases are sporadic but there are several reports of pedigrees compatible with autosomal dominant inheritance. None of the available pedigrees is large enough individually or collectively to produce a significant lod score with linked DNA markers. Various karyotypic anomalies have been reported, but there is no consistent breakpoint and very few of these cases would satisfy the strict diagnostic criteria delineated in table 1 . The exception is the apparently balanced de novo translocation, $t$ ( 3 ; 6) (p21;p21), described by Schrander-Stumpel et $a l^{12}$ Cole et $a l^{13}$ suggested that $3 \mathrm{p} 21$ could be a candidate locus after the identification of small cell carcinoma of the lung in a 23 year old non-smoker with Sotos syndrome. However, no further karyotypic abnormalities of this region have been reported and molecular studies have not identified evidence of allelic loss or altered fragments (unpublished data).

Beemer et al $^{14}$ reported two cases diagnosed as Sotos syndrome who, on subsequent investigation, were shown to have fragile $\mathrm{X}$ syndrome. Several papers have since suggested that this may be a common cause of the "Sotos phenotype". To exclude fragile X syndrome as a cause of our patients' phenotype, we have investigated them cytogenetically for the presence of fragile sites on the X chromosome. We have also used molecular genetic techniques to exclude the presence of the fragile $\mathrm{X}-\mathrm{A}$ trinucleotide repeat expansion mutation. ${ }^{15}$

The clinical features of Sotos syndrome (growth disorder with few structural abnormalities, behavioural anomalies, develop-

Table 1 Diagnostic criteria for Sotos syndrome Characteristic facial gestalt, plus at least three of the following

(1) Height $>97$ th centile on 2 consecutive measurements at least 1 year apart

2) Head circumference $>97$ th centile

(3) Bone age $>90$ th centile

(4) Developmental delay 
Table 2 Informative markers per chromosome for each of 29 Sotos syndrome patients. Figures in table body are the number of markers that were fully informative in each patient. $(S)$ denotes that at least one pair of maternally and paternally semiinformative markers were found. The last row gives the total number of uninformative chromosomes for each patient

\begin{tabular}{|c|c|c|c|c|c|c|c|c|c|c|c|c|c|c|c|c|c|c|c|c|c|c|c|c|c|c|c|c|c|}
\hline \multirow[t]{2}{*}{ Chromosome } & \multicolumn{29}{|c|}{ Patient } \\
\hline & 1 & 2 & 3 & 4 & 5 & 6 & 7 & 8 & 9 & 10 & 11 & 12 & 13 & 14 & 15 & 16 & 17 & 18 & 19 & 20 & 21 & 22 & 23 & 24 & 25 & 26 & 27 & 28 & 29 \\
\hline 1 & 1 & 1 & 2 & 2 & 1 & 2 & 1 & 1 & 3 & 1 & 2 & 1 & 0 & 2 & 1 & 2 & 2 & 2 & 1 & 1 & 1 & 1 & (S) & 1 & 2 & 1 & 1 & 1 & 2 \\
\hline 2 & 1 & 1 & 2 & 1 & 2 & 1 & 1 & 1 & 1 & 2 & 1 & 1 & 1 & 1 & 2 & 1 & 1 & 1 & 1 & 2 & 1 & 1 & (S) & 2 & 2 & 2 & 1 & 1 & 2 \\
\hline 3 & 2 & 2 & 1 & 2 & 1 & 1 & 0 & 2 & 2 & 1 & 1 & 1 & 1 & 2 & 1 & 1 & 1 & 1 & 2 & 2 & 1 & 1 & i & 1 & 1 & 1 & 1 & 1 & 1 \\
\hline 4 & 2 & 1 & 2 & 2 & 2 & 2 & 1 & 1 & 2 & 1 & 1 & 1 & 1 & 1 & 1 & 1 & 1 & 2 & 1 & 1 & 2 & 1 & 1 & 1 & 1 & 2 & 1 & 1 & 1 \\
\hline 5 & 1 & 2 & 2 & 2 & 2 & 1 & 2 & 2 & 1 & 1 & 1 & 1 & 2 & 2 & 1 & 2 & 1 & 2 & 3 & 2 & 2 & 2 & 2 & 2 & 3 & 3 & 0 & 2 & 2 \\
\hline 6 & 1 & 1 & 1 & 1 & 1 & 1 & 0 & 1 & 1 & 1 & 2 & 1 & 1 & 1 & 1 & 1 & 2 & 1 & 1 & 2 & 1 & 1 & 1 & (S) & 1 & 1 & 1 & 2 & 1 \\
\hline 7 & 2 & 2 & 2 & 1 & 2 & 2 & 1 & 1 & 1 & 0 & 2 & 2 & 2 & 2 & 1 & 1 & 1 & 2 & 1 & 1 & 1 & 2 & 1 & 1 & 1 & 1 & 1 & 2 & 1 \\
\hline 8 & 1 & 2 & 1 & 1 & 2 & 2 & 2 & 3 & 3 & 2 & 1 & 1 & (S) & 2 & 1 & 3 & 1 & 1 & 2 & 2 & 1 & 3 & 2 & 1 & 1 & 1 & 2 & 1 & 2 \\
\hline 9 & 2 & 2 & 1 & $(\mathrm{~S})$ & 2 & 1 & 1 & 2 & 3 & 3 & 2 & 1 & 2 & 1 & 1 & 1 & 1 & 1 & 1 & 1 & 1 & 1 & 1 & 1 & 1 & 1 & 2 & 1 & 1 \\
\hline 10 & (S) & $(\mathrm{S})$ & 1 & 1 & 2 & 2 & 0 & 2 & 1 & 1 & 1 & 1 & 1 & 1 & 1 & 1 & 1 & 1 & 2 & 1 & 0 & 1 & 1 & (S) & 1 & 1 & 2 & 1 & 1 \\
\hline 11 & 1 & 1 & 1 & 1 & 1 & 1 & 2 & 1 & (S) & 1 & 1 & 1 & 1 & 1 & 1 & 1 & 1 & 1 & 1 & 3 & 1 & 1 & 1 & 0 & 1 & 1 & 1 & 1 & 1 \\
\hline 12 & 0 & 1 & 1 & 2 & 1 & 2 & 0 & 1 & 2 & 3 & 2 & 2 & 1 & 2 & 1 & 1 & 1 & 2 & 1 & 1 & 1 & 1 & 1 & 1 & 1 & 1 & 1 & 1 & 1 \\
\hline 13 & 2 & 2 & 1 & 1 & 2 & 3 & 1 & 2 & 2 & 2 & 2 & 2 & 3 & 2 & 3 & 2 & 1 & 1 & 1 & 1 & 1 & 3 & 1 & 3 & 1 & 1 & 1 & 1 & \\
\hline 14 & 2 & 1 & 1 & 2 & 2 & 1 & 0 & 2 & 1 & 2 & 1 & 2 & 1 & 1 & 1 & 1 & 1 & 1 & 1 & 2 & (S) & 1 & 1 & 1 & 2 & 1 & 2 & 2 & 1 \\
\hline 16 & 2 & 3 & 2 & 2 & 1 & 1 & 1 & 2 & 1 & 1 & (S) & 1 & 2 & 1 & 1 & 2 & 2 & 2 & 1 & (S) & 2 & 3 & 1 & 3 & 1 & 3 & 2 & 1 & \\
\hline 17 & 1 & 1 & 1 & 1 & 1 & 1 & 0 & 1 & 1 & 1 & i & 1 & 1 & 1 & 1 & 1 & 1 & 1 & 1 & 1 & 1 & 1 & 1 & (S) & 1 & 1 & 1 & 1 & 1 \\
\hline 18 & 0 & 1 & 1 & 1 & 2 & 2 & 0 & 2 & 2 & 2 & 2 & 1 & 2 & 3 & 1 & 3 & 3 & 2 & 2 & 2 & 1 & 3 & 1 & 1 & 2 & 3 & 2 & 2 & 2 \\
\hline 19 & 2 & 1 & 1 & 1 & 1 & 1 & 0 & 1 & 1 & 1 & 1 & 1 & 2 & 2 & 2 & 2 & 2 & 1 & 1 & 2 & 1 & 1 & (S) & 2 & 1 & 2 & 1 & 1 & 1 \\
\hline 20 & 1 & 1 & 1 & 1 & 1 & 1 & 1 & 1 & 1 & 1 & 1 & 1 & 1 & 1 & 1 & 1 & 1 & 1 & 1 & 1 & 1 & (S) & & 1 & (S) & 1 & 1 & 1 & 1 \\
\hline 21 & 1 & 1 & 1 & 1 & 1 & 1 & (S) & 1 & 1 & 1 & 2 & 1 & 1 & 0 & 1 & 1 & 1 & 1 & 1 & 1 & 1 & 2 & 1 & (S) & 2 & 1 & 1 & 1 & (S) \\
\hline & 1 & 1 & 1 & 1 & 1 & 1 & (S) & 1 & 1 & 1 & 1 & 1 & 1 & 1 & 1 & 1 & 1 & 1 & 2 & 1 & 1 & 1 & 1 & 0 & 1 & 1 & 1 & 1 & 1 \\
\hline $\begin{array}{l}\text { Uninformative } \\
\text { chromosomes }\end{array}$ & 1 & - & - & - & - & - & 8 & - & - & 1 & & & 1 & 1 & & - & & & - & & & - & & 2 & 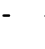 & & 1 & - & \\
\hline
\end{tabular}

mental delay, and mainly sporadic occurrence) show similarities to Prader-Willi, Angelman, Beckwith-Weidemann, and Silver-Russell syndromes. This has led to speculation that Sotos syndrome and other disorders with broadly similar features may be caused by UPD for other chromosomes. ${ }^{1617}$ We have therefore investigated UPD as a mechanism in the aetiology of Sotos syndrome. In order to find cases of UPD, we have attempted to determine the parental origin of all autosome pairs (except chromosome 15) in each patient using 112 chromosome specific dinucleotide repeat DNA polymorphisms. Chromosome 15 was excluded because the maternal and paternal UPD phenotypes are known. Chromosomes 7 and 11 were included, as the paternal UPD7 and maternal UPD11 phenotypes have not been described.

\section{Methods}

Twenty cases from a previous study ${ }^{11}$ plus nine cases assessed by one of us (TC) and satisfying the stringent criteria proposed by Cole and Hughes $^{11}$ (table 1) were included in the study. Genomic DNA from the 29 patients and their parents was extracted and purified from peripheral venous blood by the phenol/chloroform method. ${ }^{18}$

Genotyping was performed using the polymerase chain reaction (PCR) at Genethon (Paris) and at our own Birmingham and Cardiff laboratories. One hundred and twelve primer pairs which amplified dinucleotide repeat polymorphisms on all human chromosomes (except 15 and $\mathrm{X}$ ) were selected from published reports. To test for fragile $\mathrm{X}$ syndrome, primers amplifying the fragile $\mathrm{X}-\mathrm{A}$ trinucleotide repeat expansion were used, in addition to routine cytogenetic examination. All primer sequences used, and references to them, are available on request. Patient and parental DNA was amplified using the Genethon protocol ${ }^{19}$ or by a standard PCR protocol ${ }^{20}$ modified by the use of $\gamma^{33} \mathrm{ATP}$ as the isotopic label.

\section{Results}

Cytogenetic and molecular genetic examination did not show changes typical of fragile X-A syndrome in any of the patients.

All autosome pairs except chromosome 15 were studied in 29 patients with Sotos syndrome. Biparental inheritance of these was confirmed by the observation of at least one fully informative marker on the relevant autosome, or by the observation of maternal and paternal alleles at different loci on the same autosome with semi-informative markers. Biparental inheritance of every autosome pair was observed in 21 patients. Reference to tables of exact confidence gives the incidence of uniparental disomy in this population as $0.0-16.1 \%$ $(\mathrm{p}<0.05)$. In addition, biparental inheritance of all informative markers was observed in the remaining eight patients. In one of these patients, eight chromosomes were uninformative and in the remainder one or two chromosomes were uninformative (table 2).

\section{Discussion}

We have found no evidence for the presence of UPD in 29 patients with Sotos syndrome. From our data, if UPD is a cause of Sotos syndrome, the incidence is less than $16.1 \%$ $(p<0.05)$. Considering that the frequency of UPD in Angelman syndrome is $3-5 \%,{ }^{21}$ we cannot exclude UPD as a cause of Sotos syndrome.

Partial UPD for a chromosome arm or segment owing to somatic recombination, resulting in a mosaic pattern of UPD, has not been excluded. This may be difficult to show if the proportion of cells involved were low. Postzygotic exchange of chromosomal material, because of mitotic recombination, is documented in Beckwith-Weidemann syndrome in which only the $11 \mathrm{p} 15.5$ region appeared to be paternally disomic. ${ }^{822}$ To exclude this, informative markers mapping to the distal portions of each chromosome (and indeed the 
whole chromosome length, if double recombinations are to be accounted for) would need to be typed. However, the low $(<1 \%)$ frequency of asymmetry in Sotos syndrome ( $T$ Cole, unpublished data) is at variance with Beckwith-Weidemann syndrome (14\% asymmetry ${ }^{23}$ ) and this phenomenon may represent a manifestation of mosaic UPD. Therefore, mitotic recombination as an aetiological mechanism in Sotos syndrome may be less likely.

If paternal UPD were a cause of Sotos syndrome, it may only be observed at a low incidence. Paternal UPD accounts for only 3-5\% of Angelman syndrome cases, whereas about $28 \%$ of Prader-Willi syndrome cases are caused by maternal UPD. ${ }^{21}$ The difference in the rate of UPD for the same chromosome shown by these two disorders may reflect the different rates of aneuploidy observed in female and male meiosis. Aneuploidy may be present in $18-19 \%$ of human ova, compared to $3-4 \%$ of human sperm. ${ }^{24}$ If UPD is caused by corrective chromosome loss in a trisomic conception, ${ }^{125}$ then one may expect to find more cases involving maternally rather than paternally derived chromosomes.

Cytogenetic and molecular investigations have excluded fragile $\mathrm{X}$ syndrome in all our Sotos syndrome cases. We would suggest the two conditions are separate entities and that strict application of the diagnostic criteria will make errors unlikely.

The current study has not excluded UPD as a causative mechanism in Sotos syndrome, but indicates that it is unlikely to account for any more than $16 \%$ of cases, if present at all. Further clues to the possible aetiology of this condition are now required if molecular investigation is to be fruitful.

1 Spence JE, Pergaccante RG, Greig GM, et al. Uniparental disomy as a mechanism for human genetic disease. $A m$ disomy as a mechanism for hum

2 Engel E. A new genetic concept: uniparental disomy and its potential effect, isodisomy. Am 7 Med Genet 1980;6: its poten $137-43$.

3 Efstratiadis A. Parental imprinting of autosomal mammalian genes. Curr Opin Genet Dev 1994;4:265-80.

4 Cattanach BM, Kirk M. Differential activity of maternally and paternally derived chromosome regions in mice. Nature 1985;311:496-8.

5 Robinson WP, Bottani A, Yagang X, et al. Molecular, cytogenetic and clinical investigations of Prader-Willi syndrome patients. Am f Hum Genet 1991;49:1219-34.

6 Deng Z-M, Woodage T, Smart R, Smith A, Trent RJ. Novel patterns of inheritance of genetic disease are illustrated by the Angelman syndrome. Med F Aust 1993;158:813-16.

7 Malcolm S, Clayton-Smith J, Nichols M, et al. Uniparenta paternal disomy in Angelman's syndrome. Lancet 1991 337:695-7.

8 Henry I, Bonaiti-Pellie C, Chehensse V, et al. Uniparenta disomy in a genetic cancer-predisposing syndrome. Nature 1991;351:665-7.

9 Kotzot D, Schmitt S, Bernasconi F, et al. Uniparental disomy 7 in Silver-Russell syndrome and primordial growth retardation. Hum Mol Genet 1995;4:583-7.

10 Sotos JF, Dodge PR, Muirhead D, Crawford JD, Talbot NB. Cerebral giantism in childhood. N Engl F Med 1964; 271:109-16.

11 Cole TRP, Hughes HE. Sotos syndrome: a study of the diagnostic criteria and natural history. $\mathcal{F}$ Med Genet 1994; diagnostic

12 Schrander-Stumpel CTRM, Fryns JP, Hamers GG. Sotos syndrome and de novo balanced autosomal translocation syndrome and de novo balanced autosomal
$t(3 ; 6)(\mathrm{p} 21 ; \mathrm{p} 21)$. Clin Genet 1990;37:226-9.

13 Cole TRP, Hughes HE, Jeffreys M, Williams GT, Arnold $M$. Small cell lung carcinoma in a patient with Soto syndrome: are genes at $3 \mathrm{p} 21$ involved in both conditions? f Med Genet 1992;29:338-9.

14 Beemer FA, Veenema H, De Pater JM. Cerebral giantism (Sotos syndrome) in two patients with fra(X) chromosomes. Am F Med Genet 1986;23:221-6.

15 Kremer EJ, Pritchard M, Lynch M, et al. Mapping of DNA instability at the fragile $\mathrm{X}$ to a trinucleotide repeat sequence p(CCG)n. Science 1991;252:1711-14.

16 Engel E, DeLozier-Blanchet CD. Uniparental disomy, isodisomy, and imprinting: probable effects in man and strategies for their detection. Am 7 Med Genet 1991;40: 432-9.

17 Clarke A. Genetic imprinting in clinical genetics. Dev Suppl 1990;110:131-9.

18 Kunkel LM, Smith KD, Boyer SH, et al. Analysis of human $\mathrm{Y}$ chromosome specific reiterated DNA in chromosome Y chromosome specific reiterated DNA in chrom

19 Vignal A, Gyapay G, Hazan J, et al. Non-radioactive multiplex procedure for genotyping of microsatellite markers. Methods Mol Genet 1993;1:211-21.

20 Lewis JG, Weber JL, Petersen MB, et al. Linkage mapping of the highly informative DNA marker D21S156 to human chromosome 21 using a polymorphic GT dinucleotid repeat. Genomics 1990;8:400-2.

21 Cassidy SB. Diagnostic testing for Prader-Willi and Angelman syndromes. Report of the ASHG/ACMG test an technology transfer committee: American Society of Human Genetics/American College of Medical Genetics Test and Technology Transfer Committee. Am $\mathcal{F}$ Hum Genet 1996;58:1085-8.

22 Wilkie AOM, Malcolm S, Pembrey ME. Isodisomy in Beckwith-Wiedemann syndrome chromosomes. Nature 1991;353:802.

23 Elliot M, Maher ER. Beckwith-Wiedemann syndrome. $f$ Med Genet 1994;31:560-4.

24 Martin RH, Ko E, Rademaker A. Distribution of aneuploidy in human gametes: comparison between human sperm in human gametes: comparison between hum.

25 and oocytes. A CW, Erickson RP, et al. Trisomy 15 with loss of the paternal 15 as a cause of Prader-Willi syndrome loss of the paternal 15 as a cause of Prader-Wisomy. Am $f$ Med Genet 1992;51:701-8. 